\title{
Vascular regeneration by pinpoint delivery of growth factors using a microcatheter reservoir system in a rabbit hind-limb ischemia model
}

\author{
NORIHISA NITTA ${ }^{1}$, AYUMI NITTA-SEKO ${ }^{1}$, AKINAGA SONODA ${ }^{1}$, SHOBU WATANABE $^{1}$, \\ KEIKO TSUCHIYA ${ }^{1}$, KIYOSHI MURATA ${ }^{1}$ and YASUHIKO TABATA ${ }^{2}$ \\ ${ }^{1}$ Department of Radiology, Shiga University of Medical Science, Seta, Otsu, Shiga 520-2192; ${ }^{2}$ Department of Biomaterials, \\ Field of Tissue Engineering, Kyoto University, Shogoin, Sakyoku, Kyoto 606-8507, Japan \\ Received March 22, 2012; Accepted May 4, 2012
}

DOI: $10.3892 /$ etm.2012.574

\begin{abstract}
The purpose of this study was to compare the results of delivering low doses of growth factor iteratively $(20 \mu \mathrm{g}$ $\mathrm{x} 5$ ) via a reservoir system with results obtained following a single administration of $100 \mu \mathrm{g}$ of growth factor. The delivery systems using gelatin microspheres (GMS) facilitate the controlled release of drugs. The controlled release of growth factors at specific sites is essential for vascular regeneration. An ischemic hind-limb model was established in nine rabbits. A reservoir system was implanted in each rabbit. GMS impregnated with basic fibroblast growth factor (bFGF) through an indwelling 2-Fr catheter was infused in the reservoir system. The rabbits were divided into three equal groups: group 1 received $20 \mu \mathrm{g}$ iteratively (x5) via the reservoir, a single dose of $100 \mu \mathrm{g}$ growth factor was administered to group 2 and group 3 was the saline control. The therapeutic effects were evaluated by measuring the thigh temperature, blood pressure and blood flow. An immunohistological analysis was also performed for CD31. No significant difference was observed between preand post-treatment (4 weeks following bFGF infusion) in the thigh temperature, blood pressure and blood flow results from each group. Pathological analysis revealed that the number of regenerated vessels was significantly higher in the group treated iteratively with low-dose bFGF.
\end{abstract}

\section{Introduction}

Vascular regenerative therapy improves the flow of blood to ischemic tissues by inducing neovascularization in patients with vascular occlusive diseases (1-8). Therapeutic methods

Correspondence to: Dr Norihisa Nitta, Department of Radiology, Shiga University of Medical Science, Tsukinowa-cho, Seta, Otsu, Shiga 520-2192, Japan

E-mail: r34nitta@belle.shiga-med.ac.jp

Key words: vascular regeneration, basic fibroblast growth factor, reservoir system, pinpoint delivery, rabbit hind-limb ischemia model include the direct delivery of vascular growth factors including vascular endothelial growth factor, basic fibroblast growth factor (bFGF) and hepatocyte growth factor, the delivery of genes into host cells for the on-site production of vascular growth factors and the direct delivery of somatic stem cells capable of generating new vessels (9-13). The arterial infusion of vascular growth factors may be used to treat patients with vascular occlusive diseases in the future.

Hosaka et al (7) reported that in a rabbit hind-limb ischemia model, functional collateral vessels were developed upon the intra-arterial infusion of gelatin microspheres (GMS) bearing bFGF. The arterially infused, GMS-attached bFGF was released slowly and stimulated neovascularization. Vascular regeneration following a single high dose of bFGF has also been demonstrated in rabbit limb ischemia models $(6,14)$. We attempted to induce vascular regeneration by the iterative delivery of bFGF using an indwelling reservoir catheter (15). We hypothesized that, in addition to the sustained release of low-dose bFGF from GMS, the subsequent iterative infusion of free-form bFGF exerts a synergistic effect by maintaining high blood concentrations of bFGF at the target site, thereby extending the exposure time. In an effort to develop an easy-to-use test for application in a clinical setting, we used a small-diameter indwelling reservoir catheter to confirm improved vascular regeneration.

\section{Materials and methods}

Animals. The study protocol was approved by the Animal Experimentation Committee of Shiga University of Medical Science. All experiments were performed according to the Animal Care Guidelines of Shiga University of Medical Science. A total of nine healthy female Japanese white rabbits weighing between 2.5 and $3.5 \mathrm{~kg}$ were purchased from Japan SLC Inc. (Shizuoka, Japan).

Rabbit model of hind-limb ischemia. The chronic hind-limb ischemia model was created using our previously reported method (15). The rabbits were anesthetized with intramuscular injections of a mixture of ketamine hydrochloride $(25 \mathrm{mg} / \mathrm{kg}$, Ketalar 50; Sankyo Yell Yakuhin Co. Ltd., Tokyo, Japan) and 
Table I. Evaluation of collateral vessel development.

\begin{tabular}{|c|c|c|c|c|c|c|c|c|c|}
\hline \multirow[b]{2}{*}{$(\mathrm{Lt} / \mathrm{Rt})$} & \multicolumn{3}{|c|}{ Group 1} & \multicolumn{3}{|c|}{ Group 2} & \multicolumn{3}{|c|}{ Group 3} \\
\hline & Pre-treatment & $\begin{array}{l}4 \text { weeks } \\
\text { following }\end{array}$ & P-value & Pre-treatment & $\begin{array}{l}4 \text { weeks } \\
\text { following }\end{array}$ & P-value & Pre-treatment & $\begin{array}{c}4 \text { weeks } \\
\text { following }\end{array}$ & P-value \\
\hline $\begin{array}{l}\text { Surface } \\
\text { temperature }\end{array}$ & $0.99(0.01)$ & $0.98(0.03)$ & 0.57 & $1.01(0.04)$ & $1.01(0.02)$ & 0.88 & $1.01(0.02)$ & $1.04(0.04)$ & 0.30 \\
\hline $\begin{array}{l}\text { Blood } \\
\text { pressure }\end{array}$ & $0.54(0.15)$ & $0.60(0.10)$ & 0.59 & $0.80(0.85)$ & $0.92(0.26)$ & 0.83 & $1.05(0.22)$ & $1.06(0.32)$ & 0.96 \\
\hline Blood flow & $0.63(0.29)$ & $0.74(0.07)$ & 0.58 & $1.18(0.81)$ & $1.18(0.39)$ & 1.00 & $0.73(0.26)$ & $1.10(0.78)$ & 0.49 \\
\hline
\end{tabular}

There are no significant differences among the three groups with respect to any of the findings. Lt, left; Rt, right. SD is indicated in parentheses.

medetomidine hydrochloride $(0.1 \mathrm{mg} / \mathrm{kg}$, Domitor, Meiji Seika Co. Ltd., Tokyo, Japan). The left femoral artery was resected from the inguinal ligament to the popliteal fossa and bifurcation of the saphenous artery. The rabbits were then maintained for 21 days on a normal diet.

Preparation of GMS and bFGF impregnation. The GMS were of optimal specification as determined in previous studies $(7,15,16)$; they were $30 \mu \mathrm{m}$ in diameter and degraded within 2 weeks. Human recombinant bFGF (group 1, $20 \mu \mathrm{g}$; group 2, $100 \mu \mathrm{g}$; Kaken Pharmaceutical Co. Ltd., Tokyo, Japan) in $30 \mu \mathrm{l}$ phosphate-buffered saline (PBS) was added to $3 \mathrm{mg}$ of the GMS at $4^{\circ} \mathrm{C}$ for $24 \mathrm{~h}$ to obtain bFGF-impregnated GMS.

Reservoir implantation. At 21 days following femoral artery resection the rabbits were anesthetized as described above and a heparin-coated standard indwelling catheter (Toyobo Co. Ltd., Osaka, Japan) was inserted using the left internal carotid artery approach. The catheter was smaller than in our previous study ( 2 vs. $4-\mathrm{Fr}$ ) (15). Prior to insertion, we placed a $2-\mathrm{mm}$ side hole $1.5 \mathrm{~cm}$ from the tip of the catheter. The catheter tip was inserted into the deep femoral artery so that the side hole was located at the branching of the internal iliac artery. The port used in our earlier study (Clinical Supply Co., Ltd. Gifu, Japan) and the indwelling 2-Fr catheter were implanted into the subcutaneous space of the nape of the neck.

Drug infusion protocols. The nine rabbits were divided into three equal groups. The animals in group 1 received $20 \mu \mathrm{g}$ bFGF-impregnated GMS and then an additional $20 \mu \mathrm{g}$ bFGF via the reservoir daily for four consecutive days (total $100 \mu \mathrm{g}$ ), a single dose of $100 \mu \mathrm{g}$ bFGF-impregnated GMS was administered to group 2 and group 3 was the saline control. The bFGF-impregnated GMS was mixed with $2 \mathrm{ml}$ of saline and infused over the course of approximately $3 \mathrm{~min}$ via the reservoir port. In the three groups, the catheter was then heparinized with $3 \mathrm{ml}$ of saline containing 20 units of heparin. In order to maintain its patency, the catheter was heparinized once daily during the treatment period. The administration of the drug via the port was possible without anesthesia.

Evaluation of collateral vessel development. Collateral vessel development was evaluated by recording the thigh tempera- ture (thermography), blood pressure and blood flow, and by pathological analysis. Evaluation procedures were carried out prior to treatment and 4 weeks after the first or only GMS administration. The rabbits were anesthetized as described above prior to the evaluation procedures.

Thermographs (Neo Thermo TVS-700, Nippon Avionics, Tokyo, Japan) were obtained at the surface of the lower abdomen and bilateral thighs. The resolution was approximately $0.08^{\circ} \mathrm{C}$ and the total number of pixels per view was $320 \times 240$. The region of interest (ROI) was set at $15 \times 15$ pixels on the inner side of the bilateral thighs to calculate the average and left-to-right ratios.

To measure the blood pressure at the popliteal artery we used an ultrasonic Doppler flow detector (ES-1000SPII, Hadeco Inc., Kanagawa, Japan). The left-to-right ratio was determined with a sphygmomanometer with a pediatric cuff.

The blood flow was recorded using the same Doppler flow detector and the left-to-right ratio was calculated.

Pathological analysis. The rabbits were sacrificed with overdose injections of pentobarbital (Nembutal, Dainippon Sumitomo Pharma Co.,Ltd. Tokyo, Japan) at 4 weeks following treatment. Histological specimens were prepared from the inner side of the left hind-limb of each rabbit. Hematoxylin and eosin staining was performed to assess the general morphology. Regenerated vessels were localized by immunohistochemical staining with monoclonal CD31 antibody as the primary antibody against endothelial cells. Cross-sections of the semi-membranous muscle of the thigh were inspected at x100 magnification. The average number of CD31-positive cells per view was counted in three consecutive views.

Statistical analysis. The temperature, blood pressure and blood flow data were analyzed using the Student's t-test. Pathological data were subjected to one-way ANOVA and the Tukey test. $\mathrm{P}<0.05$ was considered to indicate a statistically significant result. Analyses were performed with SPSS software version 11.0 (SPSS, Inc., Chicago, IL, USA).

\section{Results}

Temperature, blood pressure, blood flow and CD31-positive vessels. As listed in Table I, among the three groups there was 
Table II. Average number of CD31-positive cells in the left semimembranous muscle 4 weeks after treatment.

\begin{tabular}{|c|c|c|c|}
\hline & Group 1 & Group 2 & Group 3 \\
\hline CD31-positive cells $/ \mathrm{mm}^{2}$ & $540.32^{\mathrm{a}, \mathrm{b}}(82.51)$ & $205.69^{\mathrm{a}}(68.89)$ & $44.36(26.37)$ \\
\hline
\end{tabular}

no significant difference between the baseline values and the readings obtained at 4 weeks post-treatment with respect to the left-to-right ratios of the temperature (group 1, $\mathrm{P}=0.57$; group 2, $\mathrm{P}=0.88$; group $3, \mathrm{P}=0.30$ ), blood pressure (group $1, \mathrm{P}=0.59$; group 2, $\mathrm{P}=0.83$; group $3, \mathrm{P}=0.96$ ) or blood flow (group 1, $\mathrm{P}=0.58$; group 2, $\mathrm{P}=1.00$; group $3, \mathrm{P}=0.49$; Table I). However, pathological study of CD31-positive vessels demonstrated that the number of positive vessels was significantly higher in group 1 than the other groups $(\mathrm{P}<0.05$; Table II, Fig. 1$)$.

\section{Discussion}

We present pathological evidence that the iterative delivery of low-dose bFGF (20 $\mu \mathrm{g}$ x5) via an implanted reservoir induced vascular regeneration more effectively than a single administration of $100 \mu \mathrm{g}$. However, the evaluation methods used in this experimental study cannot be applied in a clinical setting. In efforts to make regenerative medicine relevant to interventional radiology (IR), we modified the methods of Hosaka et al (7) and Seko et al (15) to obtain more favorable regenerative results using a reservoir system for the delivery of drugs.

We introduced a 4-Fr indwelling catheter in our previous study to investigate vascular regeneration (15) and failed to observe vascular changes on angiographs and in the body surface temperature, blood pressure and blood flow. In the present study we provide pathological evidence that iterative drug administration using a reservoir effectively induced vascular regeneration. In our previous study, angiographic findings, the body surface temperature, blood pressure and blood flow were less favorable 2 weeks after placement of the reservoir. In accordance with the hypothesis that the 4-Fr catheter was too big, we used a 2-Fr indwelling catheter in the current study.

No significant differences were observed in physical findings, including the body surface temperature, blood pressure and blood flow, among the three rabbit groups. By contrast, pathological study revealed that the number of CD31-positive cells was significantly higher in rabbits treated by the iterative delivery of low-dose bFGF via the 2-Fr catheter than it was when iterative drug delivery was via the 4-Fr catheter (435.5 vessels $/ \mathrm{mm}^{2}$ vs. $159.6 / \mathrm{mm}^{2}$ ) (15). We suggest that this difference was due to replacing the larger with the smaller diameter catheter. However, the number of vessels regenerated by the single administration of bFGF was not affected by the size of the catheter; $208.9 / \mathrm{mm}^{2}$ with the $4-\mathrm{Fr}$ and $163.4 / \mathrm{mm}^{2}$ with the 2-Fr catheter. Thus, from a pathological viewpoint, iterative or fractionated administration using a small diameter catheter was more effective.
$\mathbf{A}$

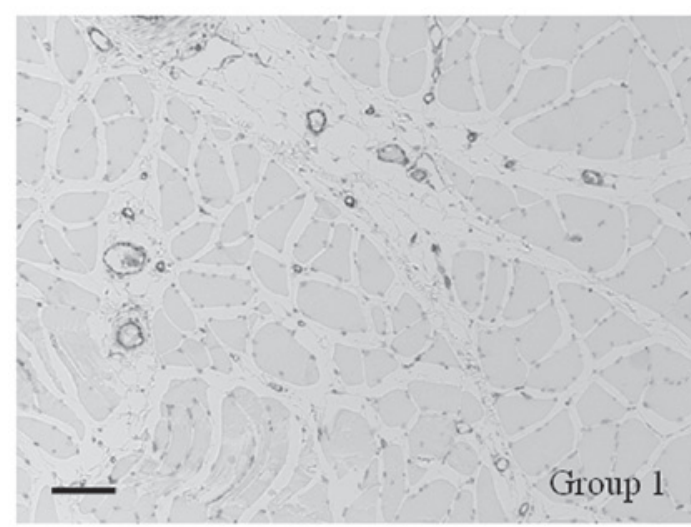

B

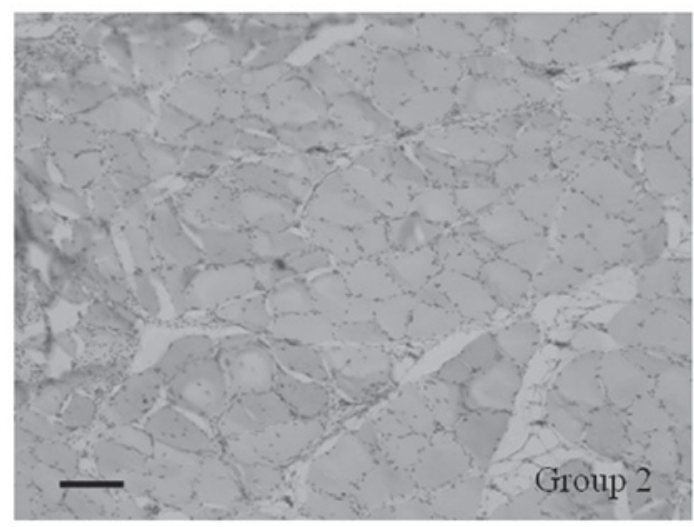

C

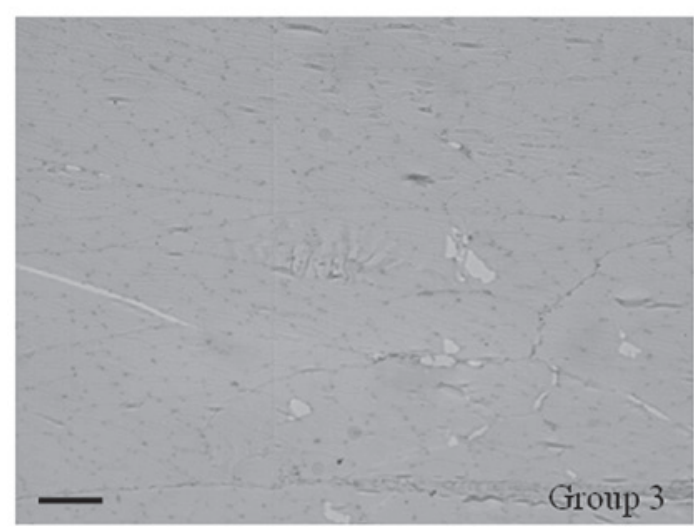

Figure 1. Immunohistochemical staining for CD31 of the left semimembranosus muscle 4 weeks after the administration of GMS. (A) Group 1 showed more regenerative vessels than (B) group 2 and (C) group 3. Bar, $100 \mu \mathrm{m}$.

Certain institutions are already practicing vascular regeneration therapy and the outcome is believed to be best determined by assessing the degree of symptom improvement $(2,17,18)$ by, for example, perfusion study using CT or MRI, contrast-enhanced ultrasonography or optical CT. We did not include angiographic findings in our efficacy evalua- 
tion as our earlier study suggested that their quantification was affected by the ROI used and thus there were variations in the ratios of vascular regeneration.

Several previous studies have reported on how bFGF bonds to GMS and is slowly released from GMS (19-22). We obtained bFGF impregnated-GMS through the same method described in these previous studies.

There are concerns that bFGF released slowly from GMS may occlude vessels in the ischemic lower limb, resulting in symptom exacerbation. To address this issue, Hosaka et al (7) studied the effects of the delivery of $3 \mathrm{mg}$ of GMS of varying sizes on the status of the lower rabbit limb. They concluded that GMS $29 \mu \mathrm{m}$ in diameter efficiently stimulated vascular regeneration without aggravating pre-existing ischemia. Based on their findings, we used $3 \mathrm{mg}$ of $30-\mu \mathrm{m}$ diameter GMS.

We placed the reservoir catheters so that the infused bFGF was distributed slowly from the internal iliac artery to the lower limb. An IR list would make it possible to pinpoint the catheter placement on vessels requiring regeneration by analyzing vascular images $(23,24)$. Our study on regenerative medicine may yield benefits for patients with vascular diseases.

In conclusion, our evaluation of drug delivery methods aimed at inducing neovascularization revealed that the iterative low-dose $(20 \mu \mathrm{g} \times 5)$ delivery via an indwelling 2-Fr catheter was more effective than the administration of a single $(100 \mu \mathrm{g})$ dose. Physical parameters, i.e. blood pressure, blood flow and temperature, were not affected by either of the delivery methods investigated.

\section{References}

1. Lara-Hernandez R, Lozano-Vilardell P, Blanes P, TorreguitartMirada N, Galmés A and Besalduch J: Safety and efficacy of therapeutic angiogenesis as a novel treatment in patients with critical limb ischemia. Ann Vasc Surg 24: 287-294, 2010.

2. Morishita R, Makino H, Aoki M, et al: Phase I/IIa clinical trial of therapeutic angiogenesis using hepatocyte growth factor gene transfer to treat critical limb ischemia. Arterioscler Thromb Vasc Biol 31: 713-720, 2011.

3. Gabr H, Hedayet A, Imam U and Nasser M: Limb salvage using intramuscular injection of unfractionated autologous bone marrow mononuclear cells in critical limb ischemia: a prospective pilot clinical trial. Exp Clin Transplant 9: 197-202, 2011.

4. Powell RJ, Comerota AJ, Berceli SA, et al: Interim analysis results from the RESTORE-CLI, a randomized, double-blind multicenter phase II trial comparing expanded autologous bone marrow-derived tissue repair cells and placebo in patients with critical limb ischemia. J Vasc Surg 54: 1032-1041, 2011.

5. Asano T, Kaneko E, Shinozaki S, et al: Hyperbaric oxygen induces basic fibroblast growth factor and hepatocyte growth factor expression, and enhances blood perfusion and muscle regeneration in mouse ischemic hind limbs. Circ J 71: 405-411, 2007.

6. Baffour R, Berman J, Garb JL, Rhee SW, Kaufman J and Friedmann P: Enhanced angiogenesis and growth of collaterals by in vivo administration of recombinant basic fibroblast growth factor in a rabbit model of acute lower limb ischemia: doseresponse effect of basic fibroblast growth factor. J Vasc Surg 16: 181-191, 1992.
7. Hosaka A, Koyama H, Kushibiki T, et al: Gelatin hydrogel microspheres enable pinpoint delivery of basic fibroblast growth factor for the development of functional collateral vessels. Circulation 110: 3322-3328, 2004.

8. Nakajima H, Sakakibara Y, Tambara K, et al: Therapeutic angiogenesis by the controlled release of basic fibroblast growth factor for ischemic limb and heart injury: toward safety and minimal invasiveness. J Artif Organs 7: 58-61, 2004.

9. Qu D, Li J, Li Y, Gao Y, Zuo Y, Hsu Y and Hu J: Angiogenesis and osteogenesis enhanced by bFGF ex vivo gene therapy for bone tissue engineering in reconstruction of calvarial defects. J Biomed Mater Res A 96: 543-551, 2011.

10. Yasuda Y, Koyama H, Tabata Y, Fujihara Y, Oba M, Uchinuma E and Takato T: Controlled delivery of bFGF remodeled vascular network in muscle flap and increased perfusion capacity via minor pedicle. J Surg Res 147: 132-137, 2008.

11. Katsuno A, Aimoto T, Uchida E, Tabata Y, Miyamoto M and Tajiri T: The controlled release of basic fibroblast growth factor promotes a rapid healing of pancreaticojejunal anastomosis with potent angiogenesis and accelerates apoptosis in granulation tissue. J Surg Res 167: 166-172, 2011.

12. Matsuura M, Okazaki K, Nishio A, et al: Therapeutic effects of rectal administration of basic fibroblast growth factor on experimental murine colitis. Gastroenterology 128: 975-986, 2005.

13. Song K, Rao NJ, Chen ML, Huang ZJ and Cao YG: Enhanced bone regeneration with sequential delivery of basic fibroblast growth factor and sonic hedgehog. Injury 42: 796-802, 2011.

14. Takeshita S, Zheng LP, Brogi E, et al: Therapeutic angiogenesis. A single intraarterial bolus of vascular endothelial growth factor augments revascularization in a rabbit ischemic hind limb model. J Clin Invest 93: 662-670, 1994.

15. Seko A, Nitta N, Sonoda A, Ohta S, Takahashi M, Murata K and Tabata Y: Vascular regeneration by repeated infusions of basic fibroblast growth factor in a rabbit model of hind-limb ischemia. AJR Am J Roentgenol 192: W306-310, 2009.

16. Tabata Y and Ikada Y: Synthesis of gelatin microspheres containing interferon. Pharm Res 6: 422-427, 1989.

17. Marui A, Tabata Y, Kojima S, et al: A novel approach to therapeutic angiogenesis for patients with critical limb ischemia by sustained release of basic fibroblast growth factor using biodegradable gelatin hydrogel: an initial report of the phase I-IIa study. Circ J 71: 1181-1186, 2007.

18. Henry TD, Hirsch AT, Goldman J, et al: Safety of a non-viral plasmid-encoding dual isoforms of hepatocyte growth factor in critical limb ischemia patients: a phase I study. Gene Ther 18: 788-794, 2011.

19. Isogai N, Morotomi T, Hayakawa S, Munakata H, Tabata Y, Ikada Y and Kamishi H: Combined chondrocyte-copolymer implantation with slow release of basic fibroblast growth factor for tissue engineering an auricular cartilage construct. J Biomed Mater Res A 74: 408-418, 2005.

20. Igai H, Chang SS, Gotoh M, et al: Regeneration of canine tracheal cartilage by slow release of basic fibroblast growth factor from gelatin sponge. ASAIO J 52: 86-91, 2006.

21. Igai $\mathrm{H}$, Yamamoto $\mathrm{Y}$, Chang SS, Yamamoto $\mathrm{M}$, Tabata $\mathrm{Y}$ and Yokomise H: Tracheal cartilage regeneration by slow release of basic fibroblast growth factor from a gelatin sponge. J Thorac Cardiovasc Surg 134: 170-175, 2007.

22. Igai H, Chang SS, Gotoh M, Yamamoto Y, Yamamoto M, Tabata $\mathrm{Y}$ and Yokomise H: Widespread and early tracheal cartilage regeneration by synchronous slow release of b-FGF and BMP-2. ASAIO J 55: 266-270, 2009.

23. Hamada A, Yamakado K, Nakatsuka A, Takaki H and Takeda K: Clinical utility of coaxial reservoir system for hepatic arterial infusion chemotherapy. J Vasc Interv Radiol 18: 1258-1263, 2007.

24. Liang HL, Huang JS, Lin YH, Lai KH, Yang CF and Pan HB: Hepatic arterial infusion chemotherapy for advanced hepatocellular carcinoma by placing a temporary catheter via the subclavian route. Acta Radiol 48: 734-740, 2007. 